\title{
A retrospective study on seven years of multiple drug treatment for paucibacillary and multibacillary leprosy, in Bayara General Hospital, Nigeria
}

\author{
L M BLOK, * L J BLOOS \& G VAN DEN BERG \\ Bayara General Hospital, Bauchi State, Nigeria
}

Accepted for publication 4 January 1991

\begin{abstract}
Summary In Bauchi State, Nigeria, a retrospective study was carried out among 973 patients on multidrug therapy (MDT), multibacillary (MB) and paucibacillary (PB), and 118 patients on a dapsone-clofazimine therapy. These patients were registered between January 1983 and September 1989. Clinical results and the problem of defaulting were investigated.

The most important conclusions drawn are: although relapses occur, MDTPB can be a valuable treatment; health education, shorter duration of treatment and permission to come less often lower the default rate, but in spite of this, the distance between home and clinic remains a problem.
\end{abstract}

\section{Introduction}

This is a retrospective study of 7 years of a multidrug therapy (MDT) programme carried out in Bayara General Hospital, Bauchi State, Nigeria. In this referral hospital for leprosy an MDT clinic was started in 1983 and modified and improved during the following years. Patients with leprosy from the whole of Bauchi State (1986: 4.2 million inhabitants; 15,000 leprosy patients registered) were referred to this hospital whenever there were difficulties with treatment. In most field clinics they would have got dapsone (DDS) monotherapy. In order to assess the efficiency of 7 years of MDT programme we intend to investigate:

the clinical results of MDT-PB and MDT-MB;

the development of results in subsequent years; and the disability score at the start of treatment.

Moreover, in order to obtain a clearer view of the influences of various factors on the rate of default and regular attendance, we intend to find out:

the effects of the introduction of health education on the rate of default;

the effect of the distance between home and clinic on regular attendance and default; whether certain patients are predestined to become defaulters.

*Correspondence: H Polaklaan 18, 1018 CS, Amsterdam, The Netherlands. 
With this study we hope to improve the MDT programme in Bayara General Hospital and to inform others about problems and solutions when starting up an MDT clinic.

\section{Patients and methods}

Patients were divided into groups according to the year in which they started treatment. At the beginning of the MDT clinic in 1983 the patients records were not quite complete. Information on disability, skin smears and attendance was sometimes missing. In 1985 treatment register books were introduced and record-keeping improved considerably. In 1986 all patients on MDT received a leprosy record chart which was kept at Bayara. All findings of examinations of skin, nerves, ST/VMT, disability grading, skin-smear results and previous treatment were documented.

Diagnosis was made using the Ridley-Jopling classification, indeterminate was rarely noted, those indeterminate patients put on MDT were classified as TT and treated accordingly. Patients diagnosed as BB, BL and LL were treated as multibacillary according to a modified WHO schedule, in which patients take the medicine six times a week instead of daily. If patients lived far away they collected their medicine every two months. This means that 1 monthly dose of rifampicin and clofazimine is taken unsupervised. Since 1986 patients diagnosed as TT and BT had been treated as paucibacillary according to the WHO schedule, with the same modifications as in MDTMB. Since 1987 patients with positive skin smears had been treated with MDT-MB. Since 1989 BT or TT patients with negative skin smears but lesions on more than 2 (out of 9) parts of the body have also been treated with MDT-MB.

Some patients were treated according to a special schedule, with dapsone and clofazimine six times a week and, since the end of 1986, with a supervised 3-monthly dose of $600 \mathrm{mg}$ of rifampicin (DC combination therapy). In early 1988 this dose was increased to $1200 \mathrm{mg}$. Patients were put on this schedule if they did not seem motivated enough to come for treatment at least once very 2 months. In particular, patients with DDSresistance were persuaded to follow this schedule so that they received at least some sort of treatment. The results of patients on this schedule were assessed separately. During this period all drugs were kept in stock.

Since 1987 patients have only been put on MDT if they pass a health education test. Patients are taught about cause and treatment of leprosy, management of lepra reactions and, if applicable, eye, hand and foot care.

In our study we admitted all patients who had started treatment between 1 January 1983 and 1 September 1989, the observations ended on 31 December 1989. From the files we collected data on age (under 15 , from 15 to 40 , and over 40 ), sex, classification, treatment, outcome of treatment and DDS resistance. Patients were considered DDS resistant if they did not respond to DDS monotherapy of if they had a recurrence of skin lesions after initial improvement during DDS monotherapy. This was assessed before patients started on MDT. Disability grading (WHO 0-3) before treatment was noted if available. Each patient obtained a total score by adding up all his disabilities. Home-toclinic distance was recorded and distinguished as follows: less than $20 \mathrm{~km}$, between 20 and $50 \mathrm{~km}, 50$ to $100 \mathrm{~km}$ and more than $100 \mathrm{~km}$. Patients were considered as defaulters if they missed 1 year of $\mathrm{MB}$ treatment or 3 months of $\mathrm{PB}$ treatment. If put on the DC combination therapy they were considered as defaulters if they had been without 
medication for more than 1 year. The overall category of defaulters includes the subgroup of defaulters after only 1, 2 or 3 visits to the clinic. Attendance was called irregular if less than $70 \%$. Since July 1989 defaulter tracing letters have been sent to defaulters and irregular attenders in order to get them back on to regular treatment. We collected data on this group too. Furthermore, we noted lepra reactions divided into type 1, mild or severe, and type 2, mild or severe. We also determined the percentage of relapses per year of follow-up, using the average follow-up period of all PB patients discharged before 1 July 1989 and MB patients discharged before 1 January 1989. Relapses were confirmed by positive skin smears. Patients were discharged after 6 months of PB treatment within a period of 9 months, if they showed no active lesions or signs of lepra reactions. Patients treated with MDT-MB were discharged after 26 months of treatment in a 3 year period if 2 negative skin smears had been taken in the past 6 months.

\section{Results}

\section{MULTIDRUG THERAPY-PB AND MB}

Altogether we observed a group of 973 patients, 234 on PB treatment and 739 on MB treatment. Of those patients 98 were under 15, 656 were between 15 and 40 and 195 were over 40 . In 24 cases age was not recorded. Treatment schedules and classification per sex are listed in Table 1.

Of all the patients on treatment $15 \cdot 3 \%$ had DDS-resistant Mycobacteriae leprae and $7 \cdot 2 \%$ were suspected of having them. Of the PB patients only $1 \cdot 2 \%$ was suspected of DDS resistance. There were no significant differences beween men and women. Results of PB and MB treatment are listed in Table 2(a) and 2(b). There was a difference in average disability between men and women, for men the average total score was 3.42 and for women it was $2 \cdot 28$. When we looked at hands and feet separately we found that more often men had a grading of 2 or 3 , whereas women more of ten had a grading of $0 . *$

In our analysis of the mechanisms that played a role in defaulting we only considered patients who started treatment between 1983 and 1987. There was a significant difference between defaulters and other patients according to home-to-clinic distance. $\dagger$ In the group living within $20 \mathrm{~km}$ from the hospital, the percentage of defaulters was lower than average, whilst the percentage was disproportionately higher in the group of people living

Table 1. Patients treatment schedules and classification per sex

\begin{tabular}{|c|c|c|c|c|c|c|c|c|}
\hline & \multicolumn{2}{|c|}{ MDT-PB } & \multicolumn{5}{|c|}{ MDT-MB } & \multirow[b]{2}{*}{ Total } \\
\hline & TT & BT & BT & BB & $\mathrm{BL}$ & LL & Un & \\
\hline M & 19 & 105 & 68 & 100 & 193 & 174 & 7 & 666 \\
\hline $\mathrm{F}$ & 19 & 91 & 36 & 37 & 76 & 41 & 7 & 307 \\
\hline Total & 38 & 196 & 104 & 137 & 269 & 215 & 14 & 973 \\
\hline
\end{tabular}

\footnotetext{
$* \chi^{2}>9$.

$+\chi^{2} 0-20 \mathrm{~km}=7 \cdot 15, \chi^{2} 100+\mathrm{km}=5 \cdot 12$.
} 
Table 2. Outcome of treatment: PB and MB patients

\begin{tabular}{|c|c|c|c|c|c|c|c|c|}
\hline & 1983 & 1984 & 1985 & 1986 & 1987 & 1988 & 1989 & Total \\
\hline \multicolumn{9}{|l|}{ PB patients } \\
\hline No. of patients & - & 1 & - & 86 & 70 & 48 & 29 & 234 \\
\hline $\mathrm{M}: \mathrm{F}$ ratio & - & $0 / 1$ & - & 1.05 & 0.94 & 1.67 & $1 \cdot 23$ & $1 \cdot 13$ \\
\hline Defaulted & - & 1 & - & 7 & 19 & 8 & 3 & 38 \\
\hline After $1,2,3$ visits & - & 1 & - & 3 & 8 & 3 & 2 & 17 \\
\hline Discharged & - & - & - & 76 & 49 & 29 & 10 & 164 \\
\hline Died & - & - & - & - & - & - & - & - \\
\hline Transferred out & - & - & - & - & - & 1 & - & 1 \\
\hline Change of diagnosis & - & - & - & 3 & - & 1 & - & 4 \\
\hline To other treatment & - & - & - & - & 2 & 4 & - & 6 \\
\hline Still on medication & - & - & - & - & - & 5 & 16 & 21 \\
\hline \multicolumn{9}{|l|}{ MB patients } \\
\hline No. of patients & 83 & 42 & 44 & 124 & 152 & 141 & 153 & 739 \\
\hline $\mathrm{M}: \mathrm{F}$ ratio & $2 \cdot 32$ & $5 \cdot 00$ & $7 \cdot 80$ & $2 \cdot 88$ & $2 \cdot 30$ & $2 \cdot 53$ & $2 \cdot 64$ & $2 \cdot 75$ \\
\hline Defaulted & 64 & 35 & 28 & 23 & 40 & 15 & - & 205 \\
\hline After $1,2,3$ visits & 51 & 23 & 7 & 8 & 19 & 8 & - & 116 \\
\hline Discharged & 17 & 4 & 7 & 68 & 14 & - & - & 110 \\
\hline Died & 1 & 1 & 1 & 3 & 5 & 3 & 2 & 16 \\
\hline Transferred out & 1 & - & - & - & 3 & 5 & 4 & 13 \\
\hline Change of diagnosis & - & - & - & - & - & - & - & - \\
\hline To other treatment & - & 1 & - & 1 & 4 & 2 & 1 & 9 \\
\hline Still on medication & - & 1 & 8 & 29 & 86 & 116 & 146 & 386 \\
\hline
\end{tabular}

Transferred out

To other treatmen

BB patients

No. of patients

After 1, 2,3 visits

Discharged

Transferred out
1

$2 \cdot 75$

10

13

$-$

386 
Table 3. Defaulters/non-defaulters and home-to-clinic distance

\begin{tabular}{lrrrrrr}
\hline & Defaulters & \multicolumn{2}{c}{ Non-defaulters } & \multicolumn{2}{r}{ Total of all patients } \\
\hline 0-20 km & 75 & $26 \cdot 5 \%$ & 208 & $73 \cdot 5 \%$ & 283 & $47 \cdot 0 \%$ \\
$20-50 \mathrm{~km}$ & 11 & $47 \cdot 8 \%$ & 12 & $52 \cdot 2 \%$ & 23 & $3 \cdot 8 \%$ \\
$50-100 \mathrm{~km}$ & 46 & $38 \cdot 3 \%$ & 74 & $61 \cdot 7 \%$ & 120 & $19 \cdot 9 \%$ \\
$100+\mathrm{km}$ & 66 & $47 \cdot 1 \%$ & 74 & $52 \cdot 9 \%$ & 140 & $23 \cdot 3 \%$ \\
Unknown & 19 & $52 \cdot 8 \%$ & 17 & $47 \cdot 2 \%$ & 36 & $6 \cdot 0 \%$ \\
\hline Total & 217 & $36 \cdot 0 \%$ & 385 & $64 \cdot 0 \%$ & 602 & $100 \cdot 0 \%$ \\
\hline
\end{tabular}

Table 4. Dapsone-clofazimine therapy. Sex and classification

\begin{tabular}{lrrr}
\hline & M & F & M+F \\
\hline BT & 5 & 2 & 7 \\
BB & 11 & 1 & 12 \\
BL & 35 & 9 & 44 \\
LL & 42 & 13 & 55 \\
\hline TOTAL & 93 & 25 & 118 \\
\hline
\end{tabular}

Table 6. Dapsone-clofazimine therapy. Home-to-clinic distance

\begin{tabular}{lrrr}
\hline & M & F & M+F \\
\hline $0-20 \mathrm{~km}$ & 2 & - & 2 \\
$20-50 \mathrm{~km}$ & - & - & - \\
$50-100 \mathrm{~km}$ & 14 & 4 & 18 \\
$100+\mathrm{km}$ & 75 & 21 & 96 \\
Unknown & 2 & - & 2 \\
\hline Total & 93 & 25 & 118 \\
\hline
\end{tabular}

Table 5. Dapsone-clofazimine therapy. Outcome of treatment

\begin{tabular}{lrrr}
\hline & M & F & M F F \\
\hline No. of patients & 93 & 25 & 118 \\
Defaulted & 20 & 2 & 22 \\
After 1, 2, 3 visits & 11 & - & 11 \\
Died & 3 & - & 3 \\
Transferred out & 3 & 1 & 4 \\
Still on medication & 67 & 22 & 89 \\
\hline
\end{tabular}

Table 7. Dapsone-clofazimine therapy. Rate of default 1983-87

\begin{tabular}{lccc}
\hline & M & F & M+F \\
\hline Patients started & 55 & 8 & 63 \\
Defaulted & 18 & 1 & 19 \\
After 1, 2, 3 visits & 11 & - & 11 \\
\hline
\end{tabular}

over $100 \mathrm{~km}$ from the hospital (Table 3, defaulters/non-defaulters and home-to-clinic distance). In the group of patients treated with MDT-PB, there were significantly fewer defaulters than in the group of patients treated with MDT-MB $(42 \cdot 7 \%$ for MB, $17 \cdot 2 \%$ for $\mathrm{PB}){ }^{*}$ Of those patients still receiving treatment $88.9 \%$ were attending regularly. In 1989 , 73 defaulter tracing letters were sent, 15 patients were traced and put back on treatment.

Of those PB patients discharged before 1 July $1989,15 \cdot 8 \%$ had a lepra reaction, of the MB group discharged before 1 January 1989 the percentage was $37 \cdot 7$. Reactions in PB patients were divided as follows: T1 mild $-5.9 \%$; T1 severe $-9.9 \%$. In MB patients T1 mild $-4.7 \%$; T1 severe $-17 \cdot 0 \%$; T2 mild $-7 \cdot 5 \%$; T2 severe $-8.5 \%$. The distribution of

$$
* \chi^{2} \mathrm{MB}=5 \cdot 6, \chi^{2} \mathrm{~PB}=17 \cdot 5 \text {. }
$$


reactions over the different classifications accounts for the differences between men and women.

Of the 160 PB patients who were discharged, 97 came regularly for follow-up. In an average observation period of $2 \cdot 14$ years after discharge, $15 \cdot 8 \%$ (24 patients) of the PB patients had a relapse $(7 \cdot 4 \%$ per year). Forty-six of the $106 \mathrm{MB}$ patients were seen regularly after discharge, their average observation period was 1.41 years, during which period $11 \cdot 2 \%$ (10 patients) had a relapse ( $7 \cdot 9 \%$ per year).

\section{DAPSONE-CLOFAZIMINE THERAPY}

We studied 118 patients (93 male, 25 female), none of them has yet been discharged, $66.9 \%$ were between 15 and $40,33 \cdot 1 \%$ were over 40 . An outline of the findings is given in Tables 4, 5 and 6 . Tracing letters were sent to 21 defaulters, resulting in 3 patients being traced and put back on treatment. Of all patients $33.9 \%$ had DDS resistant $M$. leprae, $11.0 \%$ were suspected of having them. Eighty-nine patients are still receiving treatment, 72 of them are attending regularly, $17(19 \cdot 1 \%)$ are irregular attenders.

\section{Discussion}

As regards classification there is a difference in our population between men and women which we can not explain but which is well recognized in Africa. On the $T$ side of the classification scale women are relatively numerous, whereas more men are found on the $\mathrm{L}$ side of the scale. Another difference between men and women is their disability when starting treatment, men had a higher disability score. To explain this difference we only have a hypothesis, it may be that women are more concerned about skin lesions, so that they come for treatment earlier, while men wait till nerve damage occurs. Another hypothesis is that MB leprosy leads more often to disabilities than PB leprosy.

Although DDS resistance is quite high in the group treated with MDT-MB we do not know whether this is a major problem because we are dealing with a selective population of patients referred to this hospital. Probably the percentage of DDS resistance is much lower in the field, and there is, therefore, no reason to introduce MDT-MB in a rush for all patients. A study of DDS resistance in Bauchi state is being carried out. Immediately after the introduction of MDT the default rate was extremely high, in the cohort of 1986 this rate came tumbling down. This effect can be attributed to the fact that many patients from Bayara and Bayara Leprosy camp were put on MDT in 1986 after having been on DDS monotherapy for many years. These patients had already proved to be regular attenders and were not very likely to default, moreover, they lived nearby. This effect ceased in the cohort of patients started on MDT in 1987 and the default rate increased slightly as a result, but remained low, probably because health education was started in November 1986. Default rates for the 1986 and 1987 cohorts will not increase further because very few patients are still receiving treatment. For the 1988 and 1989 cohorts default rates may still increase, but probably not greatly because all patients have been on treatment for at least 3 months and most of them are regular attenders. Until now onefifth of the defaulters responded when defaulter tracing letters were sent. It seems that once patients become defaulters it is difficult to get them back on medication. Defaulters who have restarted on MDT are likely to default again, high percentages of defaulters 
have also been described in other studies. ${ }^{4,5}$ As we hoped, there are not more defaulters in the DC combination therapy group than in the MDT-MB group. It would appear, therefore, that permission to come less often compensates for longer home-to-clinic distance. If the DC combination therapy were equally beneficial, it could be given everywhere, but then ST/VMT would be carried out less often and lepra reactions could not always be diagnosed in time.

Although the percentage of relapses after PB treatment is quite high, this kind of treatment seems to have its advantages, i.e. fewer defaulters, probably due to the shorter duration of treatment, lower costs and less overmedication. On the other hand, a more stringent selection of patients fit for PB-treatment (i.e. only TT patients and BT patients within the criteria of 1989) would probably result in fewer relapses and a better tracing of reactions and complications, because the observation period is longer and ST/VMT are carried out more often when patients are on MDT-MB. There is also a greater incentive to attend the hospital because 'pills' have to be collected. The percentage of relapses after $\mathrm{PB}$ treatment is more or less in accordance with other findings. ${ }^{7-9}$ It can also be difficult to differentiate between type 1 reactions and relapses after completing PB treatment, because skin smears are very likely to be negative in PB leprosy. We found a relatively high percentage of relapses after MDT-MB. Regarding this subject, there are not many reports available. Of ten relapses occurred within 3 or 4 months after discharge; perhaps patients were discharged too early, or medicine was not taken properly?

\section{Conclusion}

MDT-PB has the disadvantage of relapses but with a stringent selection of patients it could be a valuable treatment schedule for paucibacillary leprosy.

The establishment of a network of MDT clinics should be thoroughly planned, one would have to find a balance between 'lower quality care' close to the patient and thus less defaulting with a risk of inadequate management of reactions, and 'higher quality care' which would be less accessible with much more defaulting. Sound health education certainly has an effect on the default rate; it is also of paramount importance for the management of reactions and the prevention of disability. Health education should be given to all patients before putting them on MDT, a good way is to admit them for at least 1 week, in order to make them aware of the necessity of treatment, for instance, ascertaining how much they know by using a test. Moreover, permission to come less often as with the DC combination therapy lowers the default rate. However, distance remains a problem for many patients, and results in a higher default rate, perhaps patients could be motivated if they received some money for transport. A network of 20 MDT clinics is now being established all over Bauchi State and should solve at least part of the problem of defaulting.

\section{References}

1 WHO Study Group, Chemotherapy of leprosy for control programmes. Technical Report Series No. 675. WHO: Geneva, 1982.

2 Becx-Bleumink M. Operational aspects of MDT. Int J Lepr, 1989; 57: 540-8. 
3 Valencia LB, Luzviminda B. Social science research on social dimensions of leprosy: where are we going from here? Int J Lepr, 1989; 57: 847.

${ }^{4}$ Koticha KK, Patre BB, Kavindran Nair PR. Problems of urban leprosy control with special ref erence to case holding. Int $J$ Lepr, 1984; 52: 482-7.

${ }^{5}$ Huikeshoven H. Patient compliance in leprosy control: a necessity in old and new regimens. Int J Lepr, 1985; 53: 474-80.

6 Becx-Bleumink M. Implementation of multidrug therapy in the ALERT leprosy programme in the Shoa region of Ethiopia. First results with paucibacillary patients. Lepr Rev, 1986; 57: 111-19.

7 Samuel NM, Samuel S, Adiga RB. Treatment of paucibacillary leprosy patients with dapsone and rif ampicin. Jpn J Lepr, 1985; 54: 193-7.

8 Pavithran K. Relapse of paucibacillary leprosy after short course multidrug therapy. Ind J Lepr, 1988; 60: 225-9

9 Katoch K, Ramanathan U, et al. Relapses in paucibacillary patients after treatment with three short-term regimens containing rifampicin. Int $J$ Lepr, 1989; 57: 458-64.

10 WHO Expert Committee on Leprosy. Fourth report. Technical Report Series No. 459, 1970, p. 28.

1 Samuel NM., Samuel S., Nakami N, Murmu R. Multidrug treatment of leprosy, practical application in Nepal. Lepr Rev, 1984; 55: 265-72.

12 Kaur S., Sharma VK. Treatment of leprosy, newer concepts. Ind J Lepr, 1984; 56: 307-12.

13 Kundu SK, Hazra S.K. Chaudbury S, Chatter jee B. Evaluation of MDT with rifampicin, clofazimine and DDS in multibacillary leprosy cases. Ind J Lepr, 1984; 56: 78-85.

14 Katoch K, Ramanathan U, Natrajan M, et al. Relapses in paucibacillary patients after treatment with three short-term regimens containing rif ampin. Int J Lepr, 1989; 57: 458-64.

15 Katoch K. Current status of chemotherapy of paucibacillary cases of Hansen's disease. The star, 1989; June, July, Aug: 3-6.

16 Brakel W van et al. Relapses after multidrug therapy for leprosy: a preliminary report of 22 cases in West Nepal. Lep Rev, 1989; 60: 45-50.

\title{
Étude rétrospective sur sept ans de traitement à drogues multiples contre la lèpre paucibacillaire et par infection des multiples bacilles menée à l'Hôpital Général de Bayara, Nigeria
}

\author{
L M Blok, L J Bloos et G van den Berg
}

Sommaire Une étude rétrospective a été menée en l'État de Bauchi, Nigeria, entre 973 patients sous traitement à drogues multiples (MDT) contre la lèpre paucibacillaire (PB) et par infection de multiples bacilles (MB), et 118 patients sous une thérapie de dapsone-clofazimine. Tous ces patients ont été inscrits entre janvier 1983 et septembre 1989. Les résultats cliniques et le problème de défaillance du traitement de la part du patient sont examinés. Les conclusions entirées les plus importantes sont les suivantes: bien qu'il a des rechutes, le MDT-PB peut être utile comme thérapie; Thigiène, une réduction dans la duration du traitement et la possibilité d'offrir aux patients l'option de visiter le centre d'higiène moins souvent aident à diminuer le taux de défaut du traitement chez les patients, mais malgré cela, la distance entre le centre et la maison est toujours un problème.

\section{Estudio retrospectivo sobre siete años de tratamiento de drogas múltiples para la lepra paucibacilar y la causada por infección de múltiples bacilos en el Hospital General de Bayara, Nigeria}

\section{M Blok, L J Bloos y G van den Berg}

Resumen Se llevó a cabo un estudio retrospectivo en el estado de Bauchi, Nigeria, entre 973 pacientes bajo terapia de drogas múltiples (MDT) contra la lepra paucibacilar (PB) y la lepra por infección de múltiples bacilos (MB), y 118 pacientes bajo terapia de dapsona-clofazimina. Todos estos pacientes se registraron entre enero de 1983 y septiembre de 1989. Se investigaron los resultados clínicos y el problema de interrupción del tratamiento por parte del paciente. Las conclusiones más importantes a las que se llegaron son las siguientes: aunque haya recaídas, el tratamiento PB-MDT puede ser útil; la educación sanitaria, una menor duración del tratamiento y el of recer a los pacientes la posibilidad de visitar la clínica menos a menudo contribuyen a una disminución en el número de pacientes que abandonan el tratamiento, pero, a pesar de esto, la distancia entre el hogar y la clínica sigue siendo un problema. 